\title{
Expression of E-cadherin, Ki-67, and p53 in urinary bladder cancer in relation to progression, survival, and recurrence
}

\author{
Stanislav Ziaran, ${ }^{1}$ Stefan Harsanyi, ${ }^{2}$ Katarina Bevizova, ${ }^{3}$ Zuzana Varchulova Novakova, ${ }^{2}$ Branislav Trebaticky, ${ }^{1}$ \\ Peter Bujdak, ${ }^{1}$ Stefan Galbavy, ${ }^{4}$ Lubos Danisovic ${ }^{2}$ \\ ${ }^{1}$ Department of Urology, Faculty of Medicine, Comenius University, Bratislava \\ ${ }^{2}$ Institute of Medical Biology, Genetics and Clinical Genetics, Faculty of Medicine, Comenius University, Bratislava \\ ${ }^{3}$ Institute of Anatomy, Faculty of Medicine, Comenius University, Bratislava \\ ${ }^{4}$ Institute of Forensic Medicine, Faculty of Medicine, Comenius University, Bratislava, Slovakia
}

\begin{abstract}
Although the incidence varies with age and gender, urothelial bladder cancer is a relatively frequently occurring malignancy with variable clinical behavior that often has high recurrence rates. In this study, we analyzed the tumor tissues of 224 patients with pTa, pT1, and pT2 urinary bladder cancer. We performed a histomorphologic analysis and immunohistochemistry for p53, Ki-67, and E-cadherin, which were selected as markers of the malignant process. For pTa and pT1, univariate analyses of cancer-specific survival (CSS), progression-free survival (PFS), and recurrence-free survival (RFS) were calculated using the Kaplan-Meier method, the logrank test and Cox regression. Multivariate analysis was performed by the Cox regression analysis. Ki-67 $(\mathrm{P}<0.001)$ was significantly associated with CSS, but the highest association was shown for E-cadherin $(\mathrm{P}<0.001)$. For pT1 and pTa, the Kaplan-Meier analysis and the log-rank test revealed significantly worse PFS for patients with higher levels of Ki-67 $(\mathrm{P}<0.001)$ and lower levels of E-cadherin $(\mathrm{P}<0.001)$. Based on these obtained results, it can be clearly stated that Ki-67 and E-cadherin expression levels are associated with CSS, PFS and RFS. The clinical utility of these markers is valuable for pTa and pT1 urinary bladder cancer and should be further verified with prospective multi-center trials.
\end{abstract}

Key words: Urothelium; bladder; cancer; E-cadherin; Ki-67; p53.

Correspondence: Assoc. Prof. Dr. Lubos Danisovic, Institute of Medical Biology, Genetics and Clinical Genetics, Faculty of Medicine, Comenius University, Sasinkova 4, 81108 Bratislava, Slovakia.

Tel. +421.2.90119215. E-mail: lubos.danisovic@fmed.uniba.sk

Contributions: SZ, study conception, procurement of samples, paper drafting; BT, PB, procurement of samples; $\mathrm{SG}, \mathrm{SH}$, immunohistochemical analysis; $\mathrm{SH}, \mathrm{KB}, \mathrm{ZVN}$, data collecting and analysis; LD, study conception and paper drafting. All authors read and approved the final version of the present research manuscript.

Conflict of interest: The authors declare that they have no competing interests, and all authors confirm accuracy.

Availability of data and materials: The datasets used and/or analyzed during the current study are available from the corresponding author on reasonable request.

Ethical Approval: All samples for this retrospective study were collected in accordance with the Helsinki Declaration and were approved by the local Ethical Committee.

Patient consent for publication: Not applicable. 


\section{Introduction}

Urothelial bladder cancer (UBC) is a frequently occurring malignant disease. In the European Union, the age-standardized incidence rate (ASR - per 100,000) is 30.9 for men and 6.5 for women. ${ }^{1}$ UBC and its clinical behavior vary substantially. Currently, tumor stage, grade, and metastasis are regarded as the major prognostic factors for UBC. Although these factors are well defined, there are subgroups within the stages that exhibit different clinical behaviors and prognoses. ${ }^{2}$ Non-muscle invasive bladder cancer (NMIBC), is defined as pTa, pT1 and carcinoma in situ (CIS) UBC.

A pTa tumor is a heterogeneous disease with a large variation in reported recurrence rates $;{ }^{3}$ nevertheless, guidelines for stratification and follow up have been established. ${ }^{4}$ Within pT1 tumors, there is significant prognostic variability. In particular, for pT1G3 tumors, the natural course of the disease varies from no recurrence after resection to rapid progression and muscle-invasive and metastatic stages. This variability may compromise standard clinical management and requires individual risk stratification. ${ }^{5}$ In muscle-invasive UBC (T2-T4), all cases are high-grade urothelial carcinomas. For this reason, no prognostic information can be provided by grading. ${ }^{6}$ However, the identification of certain morphological subtypes may be important for prognosis and treatment decisions. ${ }^{7}$ Markers that can stratify patients with an unfavorable prognosis and those who may benefit from early systemic therapy are greatly needed. The currently used system is unable to accurately predict the prognosis of UBC patients with diverse and complicated tumor backgrounds. A search for novel markers to use in combination with the standard systems (stage, grade) is therefore warranted to precisely guide clinical decisions. ${ }^{8}$ The biomarkers that have been most extensively studied are E-cadherin, Ki-67, and p53.

E-cadherin is a calcium-dependent adhesion molecule, which is associated with histogenesis, differentiation and stabilization of epithelial cells. ${ }^{9}$ It belongs to the cadherin superfamily of adhesive molecules that are utilized in the structure of adherens junctions, which mediate cell-to-cell adhesion and help in maintaining the functional and structural integrity of epithelial tissues. ${ }^{10}$ Aberrations and reduction in E-cadherin expression cause ruptures in cell to cell contacts, which allow cells to migrate. ${ }^{11}$ Downregulation of E-cadherin expression causes these ruptures and leads to epithelial-to-mesenchymal transition (EMT). EMT speeds up the progression and metastasization of many epitheliumderived carcinomas (including UBC), it also increases the mesenchymal characteristics of tumor cells and subsequently promotes invasive properties and motility of these cells. ${ }^{12,13}$ These processes accelerate the progression of tumors. Aberrant E-cadherin expression was reported to accelerate the infiltration and metastasization of malignant cells. ${ }^{14}$ Furthermore, chemoresistance and radioresistance of tumor cells was linked to downregulated expression of Ecadherin, which also induces tumor cells to exhibit obvious properties of cancer stem cells. ${ }^{15}$ Normal or higher expression of E-cadherin has an inhibitory effect on EMT.

$\mathrm{Ki}-67$ is a nuclear protein that is associated with ribosomal RNA transcription and is a marker of cellular proliferation. ${ }^{16} \mathrm{Ki}-67$ is strongly expressed in the fraction of growing cancer cells, and the presence of Ki-67-positive tumor cells indicates a poor prognosis for survival and recurrence. ${ }^{17}$ An expert consensus panel has found that certain markers, such as Ki-67 and p53, can predict the recurrence and progression of bladder cancer, but the inconsistency of the available data indicates that these markers are unreliable. ${ }^{18}$

The TP53 gene [17p13] encodes a nuclear transcription factor expressed in response to various stress signals such as DNA dam- age, heat shock, hypoxia, and oncogene overexpression. Upon activation, p53 maintains the integrity and stability of the genome, cell-cycle arrest and DNA repair or (if DNA could not be repaired) leads to apoptosis. ${ }^{19}$ Extensive efforts have been made to study the effects of TP53 mutation on cancer prognosis and therapeutic responses and the role of TP53 mutations in cancer diagnosis..$^{20}$ For instance Hodgson and colleagues showed that abnormal p53 expression (null staining pattern or staining in $>50 \%$ of cells) is useful for precise prognostics of high grade UBC. ${ }^{21}$ From a more recent study by Sjödahl et al., is evident that changes in expression of p53 is associated with more aggressive molecular subtype of UBC and also with progression into advanced form of UBC. ${ }^{22}$

We conducted a retrospective study to confirm the prognostic value of E-cadherin, Ki-67, and p53 in terms of cancer-specific survival (CSS), progression-free survival (PFS), and recurrencefree survival (RFS) in a clinical subset of 224 UBC patients with five years of follow up. CSS represents the amount of time from either the date of diagnosis or the date of first treatment for a malignant disease, to the date of death caused by this disease. RFS specifically in cancer is the length of time after recieving the primary treatment for a malignant disease, that the patient survives without any signs or symptoms caused by this disease. PFS represents the amount of time after treatment for a malignant disease, that the patient lives without experiencing any worsening of his condition and without progression of his diagnosis.

\section{Materials and Methods}

\section{Patients and tumor characteristics}

The tumor tissues of 224 patients with UBC were analyzed, of which 116 were pTa, 43 were pT1, and 65 were pT2. Clinical management complied with the current EAU (European Association of Urology) guidelines. ${ }^{4,23}$ Out of 65 pT2 patients, 25 patients were treated by radical cystectomy, 11 patients were unfit/not willing to undergo further treatment, 24 patents underwent platinum-based chemotherapy and external radiation therapy. This subgroup of patients was not involved in univariate and multivariate analysis. All tumors were diagnosed according to the TNM classification. ${ }^{24}$ In NMIBC, after an initial transurethral resection of the bladder at a single center (2007-2018) and histologic assessment, a second resection was performed, and intravesical chemotherapy and adjuvant instillation of bacillus Calmette-Guérin were administered according to EAU guidelines. All samples were collected in accordance with the Helsinki Declaration and were approved by the local ethics committee.

\section{Histomorphologic analysis and immunohistochemistry}

A comprehensive retrospective histomorphologic examination of all the tumor samples according to the World Health Organization (WHO) classifications of $1973^{25}$ was performed independently by two experienced uropathologists who had no knowledge of the clinical evolution of the patients. In case of contradictory results, a re-evaluation was done and a consensus was reached. Immunohistochemistry was evaluated semiquantitatively using a scoring system with $5 \%$ steps. The areas of strongest intensity were assessed. Clinical follow-up (CSS, PFS, and RFS) of all the patients was added to our data analysis. We prepared a tissue microarray (TMA) from formalin-fixed paraffin-embedded tissue blocks; one 1.5-mm core was utilized, and the representativeness of the TMA was proven by a histopathologic comparison of the TMA with original sections of the entire tumor. The $4 \mu \mathrm{m}$ sections were prepared using a microtome and were mounted on poly Llysine-coated microscopy slides. Immunohistochemistry was car- 
ried out in a Leica ST 5050 Immunostainer (Leica, Wetzlar, Germany) utilizing the avidin-biotin peroxidase method with diaminobenzidine as the chromogen according to the instructions provided by the manufacturer.

Immunohistochemistry for E-cadherin, Ki-67, and p53 was performed using standard staining procedures as described previously. ${ }^{26}$ Each assay included positive and negative controls. E-cadherin, Ki-67, and p53 positive control slides (Cell marque, USA) were used as a positive controls. The negative control slides were probed with phosphate buffered saline instead of the primary antibody. The primary antibodies were as follows: E-cadherin: clone NCH38, DAKO, Glostrup, Denmark, dilution 1:100; Ki-67: mouse monoclonal, clone MIB-1, DAKO, Hamburg, Germany, dilution 1:50; and p53: mouse monoclonal, Bp53-12, Santa Cruz Biotechnology, Santa Cruz, CA, USA, dilution 1:1000.

Cut-off levels were chosen a priori in accordance with previous reports. ${ }^{27-29}$ Immunoreactivity to $\mathrm{Ki}-67$ was "low" if the nuclear staining of tumor cells was $\leq 15 \%$ and "high" if the staining of cells exceeded 15\%. p53 was considered "negative" if the nuclear staining of tumor cells was less than $10 \%$ and "positive" if $\geq 10 \%$. E-cadherin expression was considered "low" if the staining of tumor cells was less than $50 \%$ and "high" if staining was greater than $50 \%$.

\section{Statistical analysis}

Statistical analysis was performed using SPSS v.10.0 (SPSS Inc., Chicago, IL, USA). Kaplan-Meier method was used to estimate the survival of patients in time. The log-rank test was used to compare the survival of patients compared to the reference group. The Cox proportional risk model was used to estimate the impact of variables on survival. Logistic regression was used to estimate the probability and impact of variables on the probability of death.
The multiple logistic regression method used was Forward Selection Wald. p53, Ki-67, and E-cadherin alone and in combination were analyzed in terms of CSS, PFS and RFS. The P-values $<0.05$ were considered statistically significant. Primarily, only statistically significant results are shown.

\section{Results}

Table 1 presents the clinicopathologic variables of patients with UBC. Of 224 patients, 180 (80.4\%) were men. The median patient age was 72.5 years (range: $42-87$ years). A total of $51.8 \%$ of the patients presented with an initial diagnosis of stage $\mathrm{pTa}$ UBC, and $19.2 \%$ presented pT1 UBC. The rest of the patients were diagnosed with initial pT2 UBC (29\%). The median follow-up period was 58 months (range: $36-89$ months).

Figure 1 presents representative microphotographs from immunohistochmical analysis of E-cadherin, Ki-67, and p53 expression in urothelial bladder cancer, with positive and negative controls.

\section{Association with CSS}

The log-rank test did not show a significant association of CSS with p53 (Table 1), but statistical significance was demonstrated for Ki-67 and E-cadherin. There was no significant relationship with CSS $(\mathrm{P}=0.936)$ in the univariate Cox regression analysis. In contrast, Ki-67 $(\mathrm{P}<0.001)$ was significantly associated with CSS, but the strongest correlation was shown in the case of E-cadherin $(\mathrm{P}<0.001)$ with a hazard ratio (HR) of 0.38 (CI 0.24-0.61).

The Kaplan-Meier analysis showed that high p53 expression $(\mathrm{P}=0.936)$ was not significantly related to CSS (Figure 2). Low Ki-

Table 1. Clinicopathologic variables of patients with urothelial bladder cancer and univariate analyses regarding cancer-specific survival (reference groups are labeled).

\begin{tabular}{|c|c|c|c|c|c|c|c|c|}
\hline & & & ents & $\begin{array}{l}\text { Kaplan-M } \\
\text { (survival in }\end{array}$ & nths) & $\begin{array}{l}\text { Log-rank test } \\
\text { (P-value) }\end{array}$ & & regression \\
\hline & & n & $\%$ & Mean $(95 \% \mathrm{CI})$ & Median & & P-value & Hazard ratio $(95 \% \mathrm{CI})$ \\
\hline Gender & $\begin{array}{l}\text { Male } \\
\text { Female (ref) }\end{array}$ & $\begin{array}{l}180 \\
44\end{array}$ & $\begin{array}{l}80.4 \% \\
19.6 \%\end{array}$ & $\begin{array}{c}65.6(59.4-71.7) \\
-\end{array}$ & $\begin{array}{c}78.0 \\
-\end{array}$ & 0.316 & 0.320 & $0.80(0.50-1.26)$ \\
\hline Pattern & $\begin{array}{l}\text { Papillary } \\
\text { Solid } \\
\text { Mixed (ref) }\end{array}$ & $\begin{array}{l}168 \\
32 \\
23\end{array}$ & $\begin{array}{l}75.0 \% \\
14.3 \% \\
10.3 \%\end{array}$ & $\begin{array}{l}69.5(63.2-75.8) \\
49.0(35.4-62.7) \\
43.1(26.6-59.6)\end{array}$ & $\begin{array}{l}92.0 \\
28.0 \\
30.0\end{array}$ & 0.004 & 0.005 & $\begin{array}{c}0.48(0.27-0.83) \\
0.88(0.45-1.71) \\
-\end{array}$ \\
\hline Focality & $\begin{array}{l}\text { No } \\
\text { Yes (ref) }\end{array}$ & $\begin{array}{l}117 \\
177\end{array}$ & $\begin{array}{l}47.8 \% \\
52.2 \%\end{array}$ & $\begin{array}{l}60.9(52.6-69.2) \\
66.7(59.2-74.3)\end{array}$ & $\begin{array}{l}69.0 \\
80.0\end{array}$ & 0.353 & 0.356 & $0.84(0.58-1.22)$ \\
\hline Grading & $\begin{array}{l}\text { G1 } \\
\text { G2 } \\
\text { G3 (ref) }\end{array}$ & $\begin{array}{c}55 \\
122 \\
47 \\
\end{array}$ & $\begin{array}{c}24.6 \% \\
54.5 \% \\
21 \%\end{array}$ & $\begin{array}{l}77.0(67.4-86.7) \\
64.1(56.3-71.9) \\
46.9(35.5-58.3)\end{array}$ & $\begin{array}{c}- \\
92.0 \\
31.0\end{array}$ & 0.008 & 0.003 & $\begin{array}{c}0.43(0.25-0.75) \\
0.64(0.41-0.99) \\
-\end{array}$ \\
\hline Recurrence & $\begin{array}{l}\text { Yes } \\
\text { No (ref) }\end{array}$ & $\begin{array}{c}79 \\
145\end{array}$ & $\begin{array}{l}35.3 \% \\
64.7 \%\end{array}$ & $\begin{array}{l}55.3(46.0-64.6) \\
68.0(61.1-74.8)\end{array}$ & $\begin{array}{l}46.0 \\
80.0\end{array}$ & 0.069 & 0.072 & $\begin{array}{c}1.42(0.97-2.07) \\
-\end{array}$ \\
\hline Stage & $\begin{array}{l}\text { Ta } \\
\text { T1 } \\
\text { T2a } \\
\text { T2b (ref) }\end{array}$ & $\begin{array}{l}116 \\
43 \\
48 \\
17\end{array}$ & $\begin{array}{c}51.8 \% \\
19.2 \% \\
21.4 \% \\
7.6 \%\end{array}$ & $\begin{array}{l}79.2(72.4-86.0) \\
46.0(35.0-56.9) \\
50.4(37.6-63.3) \\
35.3(21.2-49.4)\end{array}$ & $\begin{array}{c}- \\
42.0 \\
23.0 \\
28.0\end{array}$ & $<0.001$ & $<0.001$ & $\begin{array}{c}0.25(0.14-0.46) \\
0.68(0.36-1.29) \\
0.64(0.34-1.19) \\
-\end{array}$ \\
\hline Invasivity & $\begin{array}{l}\text { Yes } \\
\text { No (ref) }\end{array}$ & $\begin{array}{l}109 \\
115\end{array}$ & $\begin{array}{l}48.7 \% \\
51.3 \%\end{array}$ & $\begin{array}{l}47.4(39.4-55.4) \\
79.8(73.0-86.5)\end{array}$ & 28.0 & $<0.001$ & $<0.001$ & $\begin{array}{c}2.15(1.97-4.34) \\
-\end{array}$ \\
\hline p53 & $\begin{array}{l}<10 \% \\
\geq 10 \% \text { (ref) }\end{array}$ & $\begin{array}{c}13 \\
211\end{array}$ & $\begin{array}{c}5.8 \% \\
94.2 \%\end{array}$ & $\begin{array}{l}66.2(47.1-85.3) \\
63.8(58.0-69.7)\end{array}$ & $\begin{array}{l}78.0 \\
78.0\end{array}$ & 0.936 & 0.936 & $\begin{array}{c}0.97(0.45-2.09) \\
-\end{array}$ \\
\hline Ki-67 & $\begin{array}{l}\leq 15 \% \\
>15 \%(\text { ref })\end{array}$ & $\begin{array}{c}73 \\
151\end{array}$ & $\begin{array}{l}32.6 \% \\
67.4 \%\end{array}$ & $\begin{array}{l}81.3(73.8-88.8) \\
54.8(47.8-61.7)\end{array}$ & 42.0 & $<0.001$ & $<0.001$ & $\begin{array}{c}0.38(0.24-0.61) \\
-\end{array}$ \\
\hline E-cadherin & $\begin{array}{l}\leq 50 \% \\
>50 \% \text { (ref) }\end{array}$ & $\begin{array}{c}69 \\
155\end{array}$ & $\begin{array}{l}30.8 \% \\
69.2 \%\end{array}$ & $\begin{array}{l}45.8(36.2-55.3) \\
71.9(65.4-78.4)\end{array}$ & 26.0 & $<0.001$ & $<0.001$ & $\begin{array}{c}2.17 \text { (1.49-3.17) } \\
-\end{array}$ \\
\hline
\end{tabular}


$67(\mathrm{P}<0.001)$ and normal E-cadherin $(\mathrm{P}<0.001)$ expression is significantly related to improved CSS (Figures 3 and 4). Table 2 presents a multiple logistic regression (Forward Selection Wald) analysis of the UBC clinicopathological variables, where Ki-67 and Ecadherin were significantly associated with CSS.

\section{Association with PFS}

Kaplan-Meier analysis and log-rank test showed significantly worse PFS for patients with higher levels of Ki-67 and lower levels of E-cadherin compared to a reference group with inverted values as shown in Table 3 and Figure 5.

Table 2. Multiple logistic regression analysis of p53, E-cadherin and Ki-67 expression of NMIBC patients in relation to CSS.

\begin{tabular}{lcccc}
\hline Method & Variable & P-value & Odds ratio (OR) & 95\% CI \\
& Ki-67 & 0.007 & 0.406 & $0.210-0.0785$ \\
& E-cadherin & 0.010 & 2.391 & $1.227-4.657$ \\
Multiple logistic regression (Forward Selection Wald) & Age & 0.001 & 1.049 & $1.020-1.080$ \\
& p53 & 0.155 & 2.743 & $0.782-9.623$ \\
& Gender & 0.702 & 0.124 & $0.509-2.480$ \\
& Grading & 0.089 & 0.918 & $0.257-1.455$ \\
& Pattern & 0.262 & 0.576 & $0.216-1.679$ \\
\hline
\end{tabular}

NMIBC, non-muscle invasive bladder cancer; CSS, cancer-specific survival.
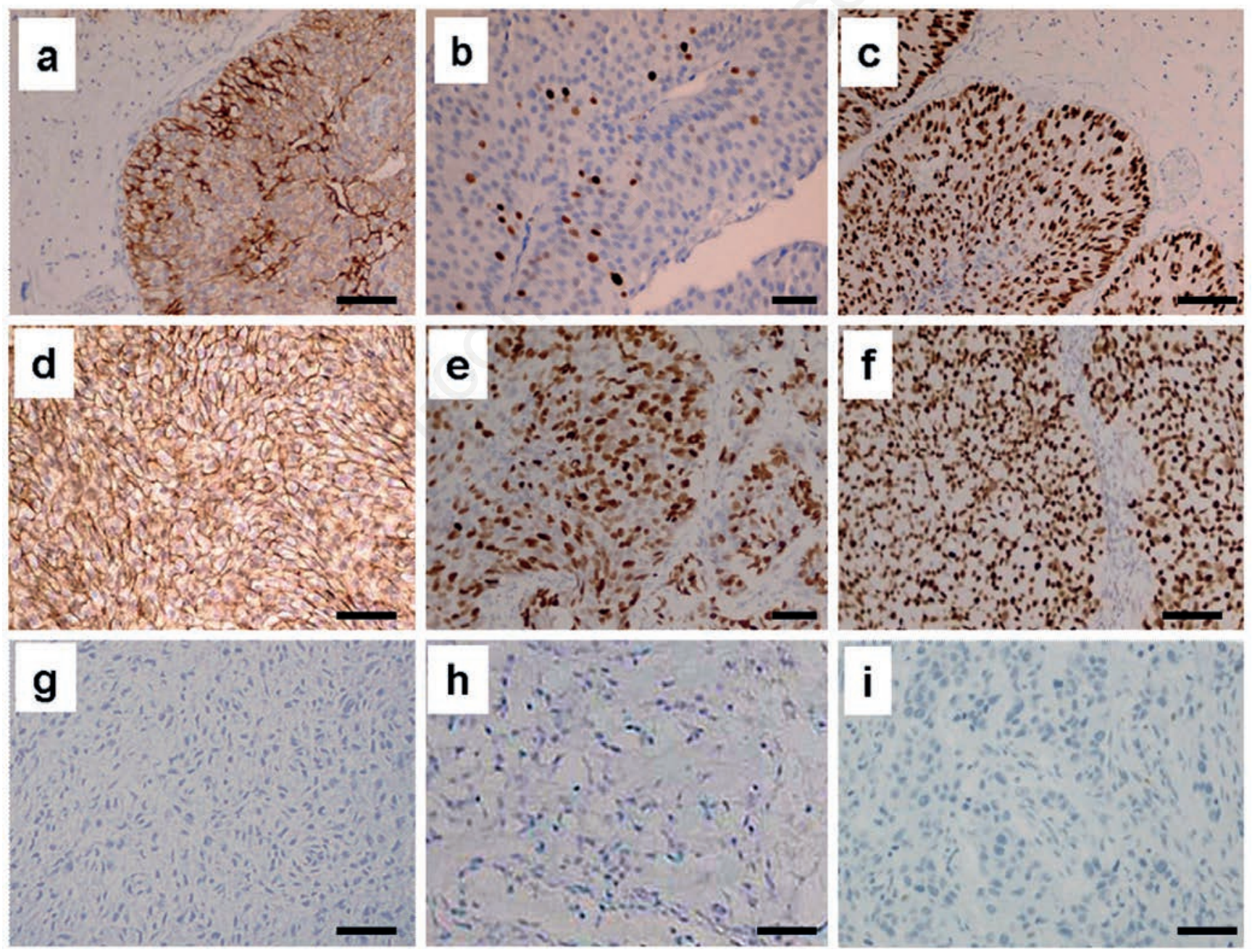

Figure 1. Representative microphotographs of E-cadherin (a), Ki-67 (b), and p53 (c) expression in urothelial bladder cancer (UBC). Positive and negative controls, respectively, for each biomarker: E-cadherin (d,g); Ki-67 (e,h); p53 (f,i). Scale bars: $100 \mu \mathrm{m}$. 


\section{Association with RFS}

In the univariate logistic and Cox regression analyses, p53, Ki67 and E-cadherin did not show statistical significance. Table 4 indicates that lower E-cadherin and higher Ki-67 expression levels significantly decreased the time to recurrence in patients with UBC compared to the reference group with inverted values.

\section{Discussion}

UBC, stages pTa and pT1, is a disease with heterogeneous and variable clinical behavior (recurrence and progression), and risk groups have been created to improve clinical management. ${ }^{2-4}$ However, optimal treatment decisions and clinical management remain a challenge, especially for pT1 UBC patients. ${ }^{5,30}$ As uncertainties remain in the prediction of clinical outcome in $\mathrm{pTa} U \mathrm{UBC}$, it is very important to search for alternative ways in diagnostics, e.g. molecular diagnostics to improve the stratification of these patients. $^{31}$

Many different markers (including proliferation markers) have already been studied in association to UBC. Most of these studies have shown that reduced expression of E-cadherin has an ill effect on prognosis in patients with UBC. ${ }^{32,33}$ A minority of studies on markers reported no association of poor prognosis and aberrant $\mathrm{E}$ cadherin expression. ${ }^{34}$ Several studies and meta-analyses have confirmed that reduced E-cadherin expression is significantly correlated with a poor prognosis in breast cancer, gastric cancer, and head and neck squamous cell carcinoma ${ }^{7,35}$ and that reduced E-cadherin expression significantly predicted unfavorable overall survival, PFS, and RFS. ${ }^{8}$

In univariate statistical analyses, our data showed that a low expression level of E-cadherin is associated with worse CSS in the pT1 UBC patients. In the multivariate analysis, a low expression level of E-cadherin was an independent predictor of worse CSS. This is in concordance with most other studies.

In $\mathrm{pTa}$ and $\mathrm{pT} 1$ bladder tumors, significant correlations between the Ki-67 index and tumor recurrence, progression, and CSS has been described. ${ }^{36}$ Our study indicated that patients with altered (higher) expression levels of Ki-67 were associated with a worse histopathology of pT1 UBC and a worse outcome. ${ }^{37}$ In addition, $\mathrm{Ki}-67$ positivity is prognostic for predicting tumor recurrence and progression. A combination of EORTC (European Organization for Research and Treatment of Cancer) risk scores and the expression of $\mathrm{Ki}-67$ can improve the risk stratification for both recurrence and progression in NMIBC. Moreover, recent meta-analysis showed that a high Ki-67 expression level was associated with poor RFS, poor PFS, and a short CSS for pTa UBC patients. $^{38}$
Ki-67 has also been studied in correlation with other markers. In the largest series of pT1 UBC patients analyzed to date, Ki-67 and CK20 have been shown to be potential prognostic markers improving the risk stratification of pT1 UBC. These markers are among the reliable indicators of biologic aggressiveness and may contribute to decision making regarding the therapeutic approach for pT1 UBC. ${ }^{39}$ Our data show that Ki-67 is an independent marker

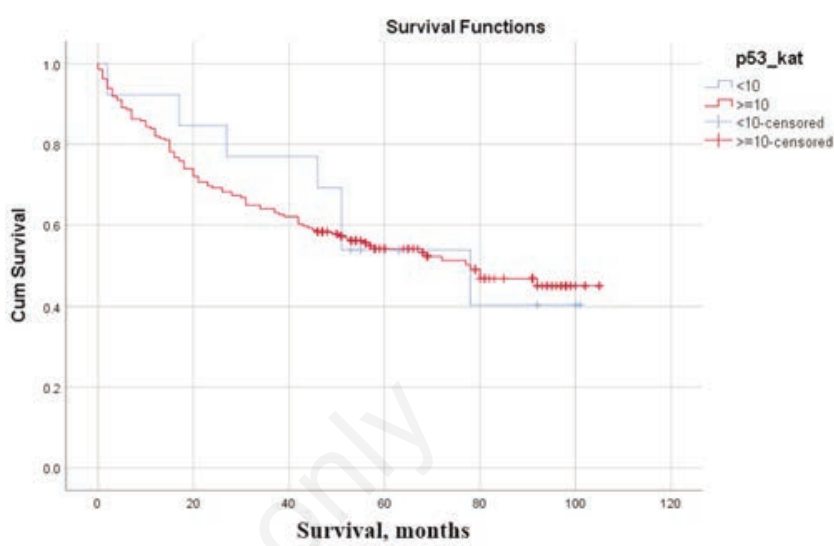

Figure 2. Kaplan-Meier analysis of p53 NMIBC patients in relation to CSS. (Log-rank P-value $=0.936)$.

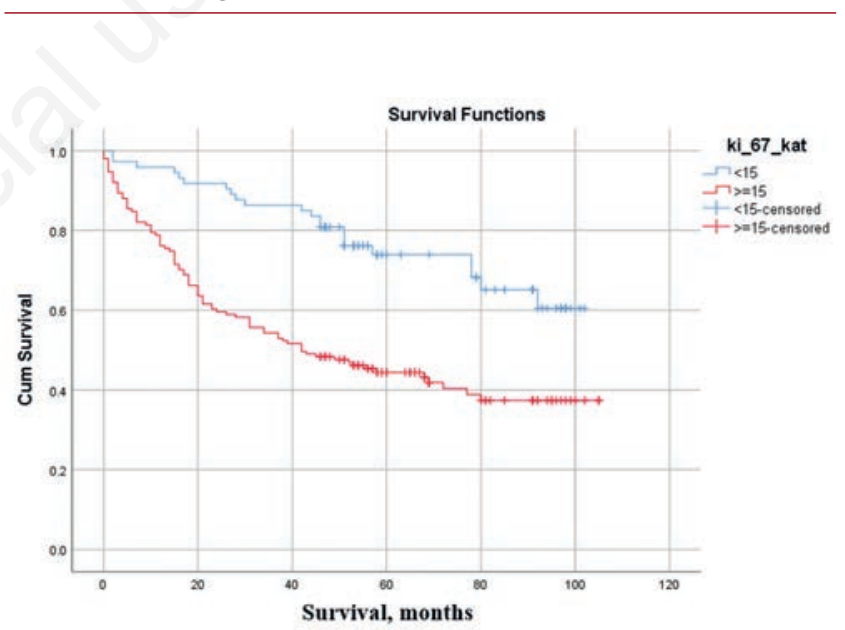

Figure 3. Kaplan-Meier analysis of Ki-67 NMIBC patients in relation to CSS. (Log-rank P-value $<0.001$ ).

Table 3. Univariate statistical analysis regarding progression-free survival of NMIBC patients analysed by Kaplan-Meier analysis and log-rank test.

\begin{tabular}{lcccc} 
Variable & \multicolumn{2}{c}{$\begin{array}{c}\text { Kaplan-Meier } \\
\text { (time until progression measured in months) }\end{array}$} & $\begin{array}{c}\text { Log-rank test } \\
\text { (P-value) }\end{array}$ \\
p53 $<10 \%$ & $66.2(44.0-111.9)$ & 64.0 & 78 & 0.834 \\
Ki-67 $>15 \%$ & $54.8(22.8-61.1)$ & 64.0 & 42 & $<0.001$ \\
\hline E-cadherin $<50 \%$ & $45.8(11.7-40.2)$ & 64.0 & 26 & $<0.001$ \\
\hline
\end{tabular}

NMIBC, non-muscle invasive bladder cancer. 
of CSS and PFS. Genetic instability with mutations in and the inactivation of the p53 tumor suppressor gene characterizes a prognostically unfavorable group of UBC patients. ${ }^{40}$ Mutations result in p53 nuclear accumulation and overexpression detectable by immunohistochemistry. In UBCs of different stages, p53 has been described as an independent predictor of cancer-specific mortality. ${ }^{41}$ A meta-analysis of p53 as a prognostic marker could not reveal sufficient evidence to recommend the routine use of $\mathrm{p} 53$ as a marker for patient outcomes in $\mathrm{BC},{ }^{42}$ and a study that included 309 patients with pT1 UBC reached the same conclusion. ${ }^{39}$ In the present series, we found no association of p53 expression with CSS, PFS or RFS. In addition, Ki-67, p53, and E-cadherin in combination have been extensively studied. A study that analyzed NMIBC found that the combined use of p53 and Ki-67 had a predictive value in NMIBC recurrence. The expression of p53 and Ki67 could be used to predict the risk of NMIBC recurrence postoperatively. ${ }^{43}$ p53 can provide $33 \%$ more information than that obtained with classical prognostic factors alone, and positivity for p53 has a prognostic value in predicting the progression of $\mathrm{pT} 1$ UBC tumors. ${ }^{44}$ However, the correlation of p53 expression with stage and grade has been questioned, either alone or in combination with $\mathrm{Ki}-67 .{ }^{45}$ In the present study, a high Ki-67 proliferation index combined with abnormal E-cadherin expression was correlated with worse survival rates compared with tumors with a low proliferation index and normal E-cadherin expression.

As mentioned above, controversy for the use of these biomarkers still exists. In our opinion, future research should focus on prospective multicenter studies to reduce bias and the combination of markers to develop a panel of markers that can accurately predict the prognosis and clinical behavior of NMIBC. These markers are greatly needed.

The limitations of the present analysis include that this study was done retrospectively. Additionally, it is well known that tumor distribution may vary in the tissue cores used for the construction of the TMA. This leads to a variable number of spots being tumorfree in the deeper sections, resulting in a decreased number of analyzable spots. In our study, approximately $15 \%$ of the analyzable tumor tissue was lost due to this technical drawback. The present data warrant prospective series with case-by-case staining in light of these limitations.

In conclusion, the present analysis of immunohistochemical markers for pT1 UBC demonstrates that Ki-67 and E-cadherin are potentially predictive of CSS in pT1 UBC. Our data showed that $\mathrm{Ki}-67$ is an independent marker of tumor progression in pTa and pT1 UBC. The analysis of Ki-67 and E-cadherin as combined factors can potentially improve the risk stratification of pT1 UBC regarding CSS. Our data suggest a potential role of Ki-67 and Ecadherin alone and in combination for predicting a worse CSS rate in pT1 UBC that may prompt more radical treatment in these patients. Ki-67 is also related to a worse PFS in pTa and pT1 patients, making Ki-67 a very valuable marker in UBC prognosis. We advocate further research to establish a panel of markers that could be used for better clinical management and prediction for patients with pT1 UBC.

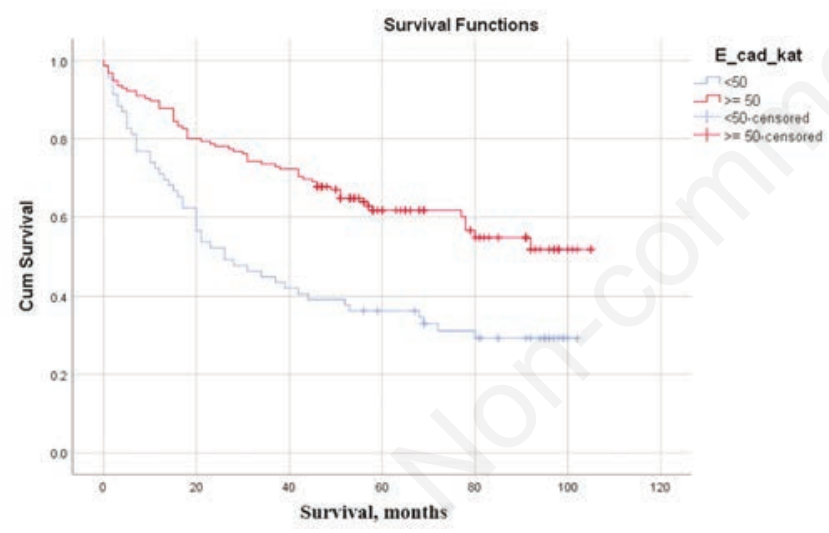

Figure 4. Kaplan-Meier analysis of E-cadherin NMIBC patients in relation to CSS. (Log-rank P-value $<0.001)$.

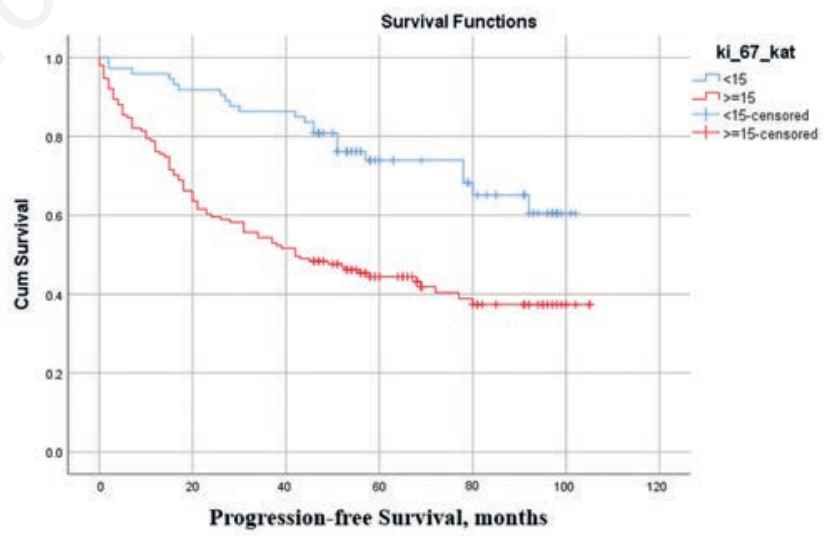

Figure 5. Kaplan-Meier analysis of Ki-67 NMIBC patients in relation to PFS. (Log-rank P-value $<\mathbf{0 . 0 0 1 )}$.

Table 4. Univariate statistical analysis regarding recurrence-free survival of NMIBC patients analysed by the Kaplan-Meier method and log-rank test.

\begin{tabular}{|c|c|c|c|c|}
\hline Variable & (time & $\begin{array}{l}\text { Kaplan-Meie } \\
\text { rence measu }\end{array}$ & & $\begin{array}{l}\text { Log-rank test } \\
\text { (P-value) }\end{array}$ \\
\hline & Mean $(95 \%$ CI) & Mean (ref) & Median & \\
\hline p $53<10 \%$ & $51.3(29.2-73.5)$ & 57.6 & 27 & 0.666 \\
\hline Ki-67> 15\% & $49.1(42.1-56.0)$ & 57.6 & 31 & $<0.001$ \\
\hline E-cadherin < 50\% & $41.4(32.0-50.6)$ & 57.6 & 21 & $<0.001$ \\
\hline
\end{tabular}

NMIBC, non-muscle invasive bladder cancer. 


\section{Acknowledgements}

This research was funded by the grant VEGA no. 1/0207/16.

\section{References}

1. Ferlay J, Colombet M, Soerjomataram I, Dyba T, Randi G, Bettio M, et al. Cancer incidence and mortality patterns in Europe: Estimates for 40 countries and 25 major cancers in 2018. Eur J Cancer 2018;103:356-87.

2. Karaoglu I, van der Heijden AG, Witjes JA. The role of urine markers, white light cystoscopy and fluorescence cystoscopy in recurrence, progression and follow-up of non-muscle invasive bladder cancer. World J Urol 2014;32:651-9.

3. Babjuk M, Böhle A, Burger M, Capoun O, Cohen D, Compérat $\mathrm{EM}$, et al. EAU Guidelines on non-muscle-invasive urothelial carcinoma of the bladder: Update 2016. Eur Urol 2017;71:447-61.

4. Shahin O, Thalmann GN, Rentsch C, Mazzucchelli L, Studer UE. A retrospective analysis of 153 patients treated with or without intravesical bacillus Calmette-Guerin for primary stage T1 grade 3 bladder cancer: recurrence, progression and survival. J Urol 2003;169:96-100.

5. Jimenez RE, Gheiler E, Oskanian P, Tiguert R, Sakr W, Wood $\mathrm{DP}$, et al. Grading the invasive component of urothelial carcinoma of the bladder and its relationship with progression-free survival. Am J Surg Pathol 2000;24:980-7.

6. Choi W, Porten S, Kim S, Willis D, Plimack ER, HoffmanCensits J, et al. Identification of distinct basal and luminal subtypes of muscle-invasive bladder cancer with different sensitivities to frontline chemotherapy. Cancer Cell 2014;25:152-65.

7. Xie Y, Li P, Gao Y, Gu L, Chen L, Fan Y, et al. Reduced E-cadherin expression is correlated with poor prognosis in patients with bladder cancer: a systematic review and meta-analysis. Oncotarget 2017; 8:62489-99.

8. Berx G, van Roy F. Involvement of members of the cadherin superfamily in cancer. Cold Spring Harb Perspect Biol 2009;1:a003129.

9. Thiery JP, Chopin D. Epithelial cell plasticity in development and tumor progression. Cancer Metastasis Rev 1999;18:31-42.

10. Li Z, Yin S, Zhang L, Liu W, Chen B. Prognostic value of reduced E-cadherin expression in breast cancer: a meta-analysis. Oncotarget 2017;8:16445-55.

11. Ren X, Wang J, Lin X, Wang X. E-cadherin expression and prognosis of head and neck squamous cell carcinoma: evidence from 19 published investigations. Onco Targets Ther 2016;9:2447-53.

12. Bryan RT, Tselepis C. Cadherin switching and bladder cancer. J Urol 2010;184:423-31.

13. van der Horst G, Bos L, van der Pluijm G. Epithelial plasticity, cancer stem cells, and the tumor-supportive stroma in bladder carcinoma. Mol Cancer Res 2012;10:995-1009.

14. Deeb G, Wang J, Ramnath N, Slocum HK, Wiseman S, Beck $\mathrm{A}$, at al. Altered E-cadherin and epidermal growth factor receptor expressions are associated with patient survival in lung cancer: a study utilizing high-density tissue microarray and immunohistochemistry. Mod Pathol 2004;17:430-9.

15. Kong D, Li Y, Wang Z, Sarkar F. Cancer stem cells and epithelial-to-mesenchymal transition (EMT)-phenotypic cells: Are they cousins or twins? Cancers 2011;3:716-29.

16. Bullwinkel J, Baron-Lühr B, Lüdemann A, Wohlenberg C, Gerdes J, Scholzen T. Ki-67 protein is associated with ribosomal RNA transcription in quiescent and proliferating cells. J Cell Physiol 2006;206:624-35.
17. Scholzen T, Gerdes J. The Ki-67 protein: from the known and the unknown. J Cell Physiol 2000;182:311-22.

18. Habuchi T, Marberger M, Droller MJ, Hemstreet GP, Grossman HB, Schalken JA, et al. Prognostic markers for bladder cancer: International Consensus Panel on bladder tumor markers. Urology 2005;66:64-74.

19. Petitjean A, Achatz MIW, Borresen-Dale AL Hainaut P, Olivier M. TP53 mutations in human cancers: functional selection and impact on cancer prognosis and outcomes. Oncogene 2007;26:2157-65.

20. Robles AI, Harris CC. Clinical outcomes and correlates of TP53 mutations and cancer. Cold Spring Harb Perspect Biol 2010;2:a001016.

21. Hodgson A, Xu B, Downes MR. p53 immunohistochemistry in high-grade urothelial carcinoma of the bladder is prognostically significant. Histopathology 2017;71:296-304.

22. Sjödahl G, Eriksson P, Patschan O, Marzouka NA, Jakobsson $\mathrm{L}$, Bernardo $\mathrm{C}$, et al. Molecular changes during progression from nonmuscle invasive to advanced urothelial carcinoma. Int J Cancer 2019. doi: 10.1002/ijc.32737. [Epub ahead of print]

23. Alfred Witjes J, Lebret T, Compérat EM, Cowan NC, De Santis M, Bruins HM, et al. Updated 2016 EAU guidelines on muscle-invasive and metastatic bladder cancer. Eur Urol 2017;71:462-75.

24. Patriarca S, Ferretti S, Zanetti R. TNM classification of malignant tumors - eighth edition: which news? Epidemiol Prev 2017;41:140-3.

25. Eble L, Sauter G, Epstein JI, Sesterhenn IA. World Health Organization classification of tumors-pathology and genetics of tumors of the urinary system and male genital organs. IARC Press: Lyon, France, 2004; p. 359.

26. Burger M, Denzinger S, Hartmann A, Wieland WF, Stoehr R, Obermann EC. Mcm2 predicts recurrence hazard in stage $\mathrm{Ta} / \mathrm{T} 1$ bladder cancer more accurately than CK20, Ki67 and histological grade. Br J Cancer 2007;96:1711-5.

27. Esrig D, Elmajian D, Groshen S, Freeman JA, Stein JP, Chen $\mathrm{SC}$, et al. Accumulation of nuclear p53 and tumor progression in bladder cancer. N Engl J Med 1994;331:1259-64.

28. Jonat W, Arnold N. Is the Ki-67 labelling index ready for clinical use? Ann Oncol 2011;22:500-2.

29. Ellis PE, Cano SD, Fear M, Kelsell DP, Ghali L, Crow JC, et al. Reduced E-cadherin expression correlates with disease progression in Paget's disease of the vulva but not Paget's disease of the breast. Mod Pathol 2008;21:1192-9.

30. Herr HW. Tumor progression and survival in patients with T1G3 bladder tumors: 15-year outcome. BJU Int 1997,80:762-5.

31. Kiemeney LALM, Witjes JA, Heijbroek RP, Verbeek ALM, Debruyne FMJ. Predictability of recurrent and progressive disease in individual patients with primary superficial bladder cancer. J Urol 1993;150:60-4.

32. Breyer J, Gierth M, Shalekenov S, Aziz A, Schäfer J, Burger $\mathrm{M}$, et al. Epithelial-mesenchymal transformation markers Ecadherin and survivin predict progression of stage $\mathrm{pTa}$ urothelial bladder carcinoma. World J Urol 2016;34:709-16.

33. Otto W, Breyer J, Herdegen S, Eder F, Bertz S, May M, et al. WHO 1973 grade 3 and infiltrative growth pattern proved, aberrant E-cadherin expression tends to be of predictive value for progression in a series of stage T1 high-grade bladder cancer after organ-sparing approach. Int Urol Nephrol 2017; 49:431-7.

34. Zhao J, Dong D, Sun L, Zhang G, Sun L. Prognostic significance of the epithelial-to-mesenchymal transition markers ecadherin, vimentin and twist in bladder cancer. Int Braz J Urol 2014;40:179-89.

35. Xing X, Tang YB, Yuan G, Wang Y, Wang J, Yang Y, et al. The 
prognostic value of E-cadherin in gastric cancer: A meta-analysis. Int J Cancer 2013;132:2589-96.

36. van Rhijn BWG, Liu L, Vis AN, Bostrom PJ, Zuiverloon TCM, Fleshner NE, et al. Prognostic value of molecular markers, sub-stage and European Organisation for the Research and Treatment of Cancer risk scores in primary $\mathrm{T} 1$ bladder cancer. BJU Int 2012; 110:1169-76.

37. Ding W, Gou Y, Sun C, Xia G, Wang H, Chen Z, et al. Ki-67 is an independent indicator in non-muscle invasive bladder cancer (NMIBC); Combination of EORTC risk scores and Ki67 expression could improve the risk stratification of NMIBC. Urol Oncol 2014;32:42.e13-9.

38. Ko K, Jeong CW, Kwak C, Kim HH, Ku JH. Significance of Ki67 in non-muscle invasive bladder cancer patients: a systematic review and meta-analysis. Oncotarget 2017;8:100614-30.

39. Bertz S, Otto W, Denzinger S, Wieland WF, Burger M, Stöhr $\mathrm{R}$, et al. Combination of CK20 and Ki-67 immunostaining analysis predicts recurrence, progression, and cancer-specific survival in pT1 urothelial bladder cancer. Eur Urol 2014; 65:218-26.

40. Lopez-Knowles E, Hernandez S, Kogevinas M, Lloreta J,
Amoros A, Tardon A, The p53 pathway and outcome among patients with T1G3 bladder tumors. Clin Cancer Res 2006;12: 6029-36.

41. Esrig D, Elmajian D, Groshen S, Freeman JA, Stein JP, Chen $\mathrm{SC}$, et al. Accumulation of nuclear p53 and tumor progression in bladder cancer. N Engl J Med 1994;331:1259-64.

42. Malats N, Bustos A, Nascimento CM, Fernandez F, Rivas M, Puente D, et al. P53 as a prognostic marker for bladder cancer: a meta-analysis and review. Lancet Oncol 2005;6:678-86.

43. Wang L, Feng C, Ding G, Ding Q, Zhou Z, Jiang H, et al. Ki67 and TP53 expressions predict recurrence of non-muscle-invasive bladder cancer. Tumor Biol 2014;35:2989-95.

44. Queipo-Zaragoza JA, Ruiz-Cerda JL, Vera-Donoso CD, VeraSempere F, Budia-Alba A, Jimenez-Cruz JF. Prognostic value of p53, Ki-67, microstaging and microvessel density in pT1G3 bladder tumors: Creation of risk groups for progression. Scan J Urol Nephrol 2007;41:283-9.

45. Wang L, Feng C, Ding G, Zhou Z, Jiang H, Wu Z. Relationship of TP53 and Ki67 expression in bladder cancer under WHO 2004 classification. JBUON 2013;18:420-4.

Received for publication: 3 December 2019. Accepted for publication: 19 February 2020.

This work is licensed under a Creative Commons Attribution-NonCommercial 4.0 International License (CC BY-NC 4.0).

(C) Copyright: the Author(s), 2020

Licensee PAGEPress, Italy

European Journal of Histochemistry 2020; 64:3098

doi:10.4081/ejh.2020.3098 